\title{
A POSSIBILIDADE DA MEDIAÇÃO EXTRAJUDICIAL NAS RELAÇÕES TRABALHISTAS ANTE A REFORMA TRABALHISTA DE 2017
}

\author{
Rebecca Falcão Viana Alves* \\ Ana Carolina Fontes Figueiredo Mendes $^{* *}$
}

\begin{abstract}
RESUMO
O presente trabalho discute o impacto da reforma trabalhista de 2017 na possibilidade da utilização da mediação extrajudicial como método alternativo de resolução de conflito na seara do Direito do Trabalho. Foi apresentado o conceito de mediação e sua relação com a justiça obreira, além de observar o que a Lei 13.140/2015, que regulamenta a mediação, estabelece sobre tal método de ressignificação de controvérsias no âmbito das relações de trabalho. Por fim, foram mostrados os pontos principais da reforma trabalhista que, em tese, permitem a mediação extrajudicial nos conflitos individuais das relações trabalhistas.
\end{abstract}

Palavras-Chaves: Mediação; Formas Consensuais de Resolução de Conflito; Reforma Trabalhista; Direito do Trabalho; Acesso à Justiça.

\section{THE POSSIBILITY OF EXTRAJUDICIAL MEDIATION IN WORKING RELATIONS AFTER THE 2017 LABOR REFORM}

\begin{abstract}
In this essay, It will be discussed how the labour law reform bill of 2017 affects the possibility of using extrajudicial mediation in the individual labour conflicts. It will present the concept of mediation and its relation to the labour's justice. Additionally, the essay will show what the law $\mathrm{n}^{\circ} 13.140 / 2015$, which regulates mediation, speculates about the mediation in the working relationship. Lastly, It will highlight the main points in the labour law reform bill that may or may not allowed the extrajudicial mediation be used in the individual labour conflicts.
\end{abstract}

Keywords: Mediation; Consensual Approaches to Conflict Resolution; Labour Law Reform Bill; Labour Law; Access to Justice.

\section{INTRODUÇÃO}

\footnotetext{
* Mestranda no Programa de Pós-Graduação em Direito pela Universidade Federal de Sergipe. Bolsista da CAPES. Especialista em Direito do Trabalho e Previdenciário pela Faculdade Guanambi. E-mail: <rebecca.f.v.alves@gmail.com>. Rua José Luiz da Conceição, 190, cond. Ouro Verde, Jardins.

** Mestranda no Programa de Pós-Graduação em Direito da Universidade Federal de Sergipe (UFS).Bolsista de FAPITEC/SE. Mestra em Direitos Humanos, Multiculturalismo e Desenvolvimento - Universidad Pablo de Olavide (2016). Especialista em Direito Público pela Faculdade Maurício de Nassau. E-mail: <carolf.adv@hotmail.com>. Celular: (79) 999880990. Rua Edson Ribeiro, n 806, apt. 802. Edf: Mansão dos Jardins. Cep: 49025-140. Aracaju-Se. Brasil.
} 
Devido à recorrente insatisfação com o Poder Judiciário e seu método de pacificação de disputas, houve a necessidade de ter a atenção voltada para estudar algo que é antigo, não somente nas normas e leis que compõe o ordenamento jurídico pátrio como no mundo inteiro, os meios de ressignificação de conflitos.

Em virtude dessa necessidade, nos últimos anos, vem se discutindo bastante sobre como a jurisdição tradicional adquiriu uma visão adversarial das lides, de modo que os participantes - e mesmo seus representantes - atacam-se por todo o processo, tornando-o uma questão pessoal muito mais que de Direito. O processo judicial brasileiro adquiriu níveis de rivalidade e de animosidade entre as partes, que parecem ser alimentadas com a sensação de que na sentença decidirá o certo e o errado, portanto quem estiver errado sofrerá as consequências pelo equívoco.

O forte aspecto adversarial que o processo foi adquirindo ao longo dos anos é chamado de litigiosidade, a qual pode ser definida como o desejo das partes de estender os conflitos nas vias judiciais, ou simplesmente a incapacidade de resolvê-los fora do Poder Judiciário.

Em verdade, a litigiosidade e a visão adversarial do processo estão entre as causas da crise no Judiciário, juntamente com a corrupção dos servidores, a morosidade - possivelmente causada pela própria litigiosidade - e outros fatores. Graças à crise judicial, compreendeu-se ser necessário buscar meios solucionadores dos litígios com mais celeridade, consequentemente com menos litigiosidade entre as partes, além de que possibilitassem auxiliar a Justiça na construção da pacificação social aliado ao acesso à Justiça e ao respeito à dignidade humana.

A ideia de acesso à Justiça modificou-se ao longo dos últimos anos visando a encontrar formas que possibilitem o alcance do justo entre as pessoas, trazendo uma satisfação pelo alcance de respostas que podem possibilitar uma vida social mais harmônica, o que as decisões judiciais não têm conseguido alcançar, ocasionando as insatisfações com esse Poder. Entender o acesso à Justiça como novo paradigma e direito fundamental a ser perseguido para pacificação social faz parte desse estudo.

Com o crescimento do cenário descrito, foram aprovados e sancionados, em 2015, o Código de Processo Civil e a Lei $n^{\circ}$ 13.140, que tratam da mediação. Ambos trouxeram consequências para a Justiça do Trabalho, que, por sua vez precisou se adequar aos novos requisitos - contidos nas citadas leis - sobre a exigência de utilização dos meios alternativos de resolução de conflitos, especialmente, a mediação. 
Dois anos após, houve uma nova lei que também impactou a justiça obreira, a reforma trabalhista de 2017. O abalo foi forte e visivelmente político, porém, além do estrago que tal reforma fez no Direito do Trabalho, ela também trouxe novos pontos de apoio para que a justiça trabalhista usasse os métodos de ressignificação de controvérsias. Contudo, a reforma trouxe uma - até então apaziguada - discussão sobre a possibilidade de ser realizada a mediação extrajudicial no tocante a direitos individuais trabalhistas.

O presente artigo tem como objetivo compreender o impacto que a reforma trabalhista de 2017 causou na discussão da possibilidade da realização do processo de mediação extrajudicial nas relações individuais do trabalho. É para este questionamento que a presente pesquisa pretende encontrar respostas; para tanto, foi necessária uma breve explicação do que é a mediação, juntamente com à sua relação com a Justiça e o direito do trabalhador, bem como a análise sobre os impactos que a reforma trabalhista trouxe à questão da possibilidade da mediação extrajudicial nas relações individuais trabalhistas, a fim de concluir se a mediação é de fato compatível com o direito do trabalhador ou não, ou mesmo se há algo que falta para que ela seja utilizada.

Por fim, para a realização desta pesquisa, a metodologia utilizada foi, primeiramente, o levantamento bibliográfico acerca dos conceitos de acesso à Justiça, dignidade humana, direitos humanos, mediação e justiça do trabalho; logo após foi feita a pesquisa documental, sendo utilizadas fontes primárias como a lei, especialmente, as leis de mediação e a que instituiu a reforma trabalhista, com o intuito de descobrir a possibilidade da mediação na Justiça do Trabalho como forma do acesso à Justiça e de dar dignidade humana ao trabalhador.

\section{ACESSO À JUSTIÇA}

A priori, antes de adentrar na questão da possibilidade da mediação na Justiça do Trabalho, é primordial esclarecer o principal motivo de ser necessário que haja a mediação como resolução alternativa de conflitos.

A Justiça do Trabalho, como se sabe, foi criada para proteger o trabalhador na relação entre ele e o empregador, já que ele é a mais parte mais sensível dessa relação. Contudo, apesar de a justiça trabalhista vir desempenhando um louvável papel ao longo dos anos, a resolução do conflito vem sempre de uma parte alheia ao problema ocorrido, e que, 
por diversas vezes, exige uma vivência do conflito laboral e da situação social, para realmente entender qual seria a melhor solução ao caso.

Com isso, os trabalhadores começaram a fazer parte ativa das decisões judiciárias, e não o papel de meros expectadores, que apenas estão à espera da jurisdição estatal. Ademais, o acesso à Justiça não pode ser identificado apenas como o acesso ao Poder Judiciário, muito menos pode-se afirmar que a satisfação de um conflito só ocorre com a resposta estatal (AZEVEDO, 2013)

Atualmente, já há um movimento por parte da doutrina no sentido de abandonar a ideia dominante de que as normas positivadas se impõem sobre a vontade consentida, assim já há a posição de que o justo, no sentido de valor, pode e deve ser constituído consensualmente entre as partes; com isso elas constroem juntas uma solução aceitável a todos envolvidos, respeitando a normatização estatal mínima; apenas em casos em que a mediação não pode ser estabelecida consensualmente é que um terceiro, indicado pela lei poderia decidir o que seria o justo diante do conflito em concreto (AZEVEDO, 2013).

Nesse sentido, o acesso ao justo passa a ser mais democrático, permitindo que a construção do justo seja cabível a todos os envolvidos no conflito; desse modo retira-se a ideia de rivalidade presente nos processos judiciais, pois, ao final, não haverá perdedores. Também o significado da Justiça passa a ser mais amplo, já que permite que as partes criem consensualmente a decisão do que é justo no caso concreto.

Alerta-se, também, que deixar o conflito ser solucionado apenas pela aplicação lógica-jurídica-processual do Poder Judiciário acaba por impulsionar a situação de rivalidade entre os litigantes, e enfraquece ainda mais as relações sociais preexistentes entre as partes do conflito, sendo importante que, no momento da subsunção da norma ao conflito, a parte componente fundamental do conflito não seja deixada de fora da sua resolução, sendo este elemento o ser humano (AZEVEDO, 2013).

A grande exigência das formalidades para o ingresso de um procedimento público ser analisado de acordo com sua correção e justeza, nos aspectos legais e formais, pode gerar o desrespeito à dignidade humana, já que o formalismo retira a participação direta da pessoa comum, em outras palavras a pessoa comum por desconhecer um ritual é obrigada a confiar plenamente no seu advogado (VEZZULLA, 2013).

Nesse contexto, há desrespeito à dignidade humana da parte, pois esta é obrigada a configurar em um processo judicial que segue excessivamente regras preestabelecidas e é guiado com base no formalismo, mesmo na justiça do trabalho, que busca ser menos formal 
que as demais, ainda assim é bastante formal para o trabalhador comum. Desse modo, muitas vezes, para resolver o conflito o trabalhador necessitaria de um conhecimento formal, processual, e um conhecimento das legislações e de suas implicações, porém infelizmente este conhecimento está ao alcance de pouco na sociedade, por isso o trabalhador sempre estará em desvantagem num processo judicial, ainda que haja na Justiça do Trabalho o Princípio da Proteção.

Nesse sentido, a parte que desconhece os aspectos legais e formais fica fora ativamente da decisão, e o trabalhador que ingressa com ação na Justiça no Trabalho sem advogado, por vezes, acaba por perder o processo, por puro desconhecimento de como se comportar naquele ritual. Em consequência, o modelo adversarial de abordagem dos conflitos cria a falsa sensação de quem recebe a sentença favorável "vence" a ação, desmerecendo a parte que não possui o conhecimento formal. “Ou, seja, que o conceito de merecimento como base de atribuição de respeito ataca diretamente a autonomia, produzindo a humilhação que exclui uma pessoa por não ser possível de entende-la produzindo a consequente perda de sua dignidade" (VEZZULLA, 2013, p. 69).

Ademais, ainda que a Justiça do Trabalho, principalmente antes da Reforma Trabalhista de 2017, estivesse desempenhando um forte ativismo para assegurar os direitos trabalhistas, o trabalhador é que deveria desempenhar o principal papel nesse conflito, porém, acaba configurado na relação processual como uma pessoa sem autonomia e sem força na sociedade, assim a mediação na Justiça do Trabalho surge para dar novo sentido ao papel do obreiro e ressignificar as violações de direito vividos pelo trabalhador, já que esta modalidade lhe dá autonomia, empoderamento e verdadeira dignidade.

Através desse mecanismo, os direitos humanos dos trabalhadores podem ser verdadeiramente alcançados. Aqui, o significado de alcançar os direitos humanos é muito maior do que a simples obtenção a determinados objetos genéricos, pois seu significado é muito mais emancipador, já que significará a adoção de uma prática permitirá que dotar esse grupo de um instrumento jurídicos através do qual se permite o acesso aos bens necessários a serem vividos com dignidade (HERRERA FLORES, 2008).

É essencial ressaltar que Herrera Flores (2008) entende que a dignidade humana não significa o simples acesso aos bens somente para sobreviver, e sim que se deve ter acessos aos bens de forma justa e igualitária a todos para que se alcance uma vida digna de ser vivida, com isso a dignidade humana passa e ser um fim material. 
Então, somente a resolução de conflitos tornarão verdadeiro instrumentos de promoção de dignidade humana, quando as partes, principalmente a parte trabalhadora, obtiveram de forma igualitária e justa a solução ao conflito, e, como já dito, através da mediação é possível alcançar esse verdadeira o direito humano.

Alias “o acesso efetivo à justiça pode se considerar como um requisito mais básico o direito humano mais fundamental - num sistema legal igualitário moderno que pretenda garantir e não somente proclamar os direitos humanos de todos" (CAPPELLETI; GARTH 1996, p.13). Outra questão é que o sistema de justiça brasileiro é muito bom em garantir e positivar os direitos humanos, a sua efetividade ainda é um ponto falho, por isso é necessário que o acesso pleno à Justiça supere este descompasso entre o proclamado e o garantido, de fato.

Por último, cumpre desenhar que dentro do modelo adversarial de resolução de conflitos, a parte que irá encontrar a solução do justo e do conflito é um juiz. Ocorre que este juiz será alguém não escolhido pelas partes, ademais este juiz muitas vezes pode provir de uma cultura, religião e ideologia entre as partes, além de que é este quem irá reger o merecimento, decidindo quem merece no caso concreto, baseado na sua interpretação formal apresentada no processo (VEZZULLA, 2013).

Em suma, a mediação é importante meio de solução de conflitos, pois traz possibilidades de novas interações sociais, ou seja, em vez de minar relações já conflituosas, tenta apaziguá-las, dando novos significados aos conflitos, bem como fornecendo uma solução emancipadora para este, já que é encontrada pelas próprias partes, que decidem como base em sua cultura, religião, princípios e ideologia.

Nesse sentido, a mediação pode vir a dar novos rumos à Justiça do Trabalho, tão afetada pela Reforma Trabalhista de 2017, e assim garantir que os conflitos trabalhistas sejam resolvidos de modo justo para o trabalhador, e que seu direito humano e dignidade humana sejam preservados, ou restabelecidos a depender da situação, através do acesso à Justiça de forma plena, ampla e emancipadora. Assim, para reforçar a necessidade da mediação na Justiça do Trabalho, nos tópicos seguinte são delineados os aspectos desse método.

\section{MEDIAÇÃO}

A mediação é um método alternativo de resolução de conflitos, o qual, conforme a entendimento de Morais e Spengler (2008), é um processo em que um terceiro imparcial 
auxilia os participantes na resolução de uma disputa. Em outras palavras, é a aplicação da autocomposição, que é a tomada na decisão do conflito pelas partes litigantes. Consoante a Lei 13.140/15 (BRASIL, 2015), ela pode ser judicial, que ocorre dentro do Poder Judiciário, ou extrajudicial, realizada por mediadores extrajudiciais ou Câmaras de Mediação. Interessante destacar a lição de Silva (2011, p. 125), sobre estas possibilidades:

É de ressaltar, ainda que a atividade de mediação pode ser desenvolvida no âmbito extrajudicial ou judicial, sendo esta parte do sistema de administração e distribuição de justiça estadual. Fala-se, hodiernamente, em mediação paraprocessual (para = ao lado de), pretendendo introduzir no âmbito do Poder Judiciário a realização de um método complementar de composição de conflitos.

Nesse método, há a presença de um terceiro imparcial e neutro que auxilia as partes a restabelecerem seus canais de comunicação para que dessa forma tentem chegar a um acordo sobre a questão de interesse. Esse facilitador é o mediador.

A mediação de conflitos, na ótica de Tartuce (2016, p. 52), assim se define:

A mediação de conflitos é o meio consensual de abordagem de controvérsias em que uma pessoa isenta e devidamente capacitada tecnicamente para facilitar a comunicação entre as pessoas para propiciar que elas possam, a partir da restauração do diálogo, encontrar formas proveitosas de lidar com as disputas.

Diferente do que acontece na jurisdição ou na arbitragem, o mediador não tem poder de decisão, esse poder pertence aos interessados, seu principal papel é o de manter o equilíbrio entre as partes e o de restabelecer a comunicação entre os litigantes para que possam tratar da questão de interesse sem a interferência de sentimentos negativos ou de questões paralelas que atrapalham a resolução do conflito. O mediador, além de não poder decidir pelas partes, não pode apresentar soluções para elas, como informa Antônio Hélio Silva (2008), ao falar sobre como o mediador age durante o processo de mediação.

Nesse sentido, Vezzulla (2006, p. 69), exemplifica que:

A mediação de conflitos já é conhecida na maior parte do mundo como o procedimento que, associado ou não ao sistema judicial tradicional, pode ser usado na abordagem dos conflitos interpessoais. Todo os autores consultados coincidem em caracterizar esta abordagem pela ausência de formalismos e pelo que essencialmente a distingue dos outros procedimentos: estar baseado no diálogo, na cooperação e no respeito entre os participantes.

Em virtude de a mediação ser uma forma de resolução de controvérsia que trabalha com o foco no restabelecimento da comunicação entre os litigantes e seu empoderamento para que eles possam decidir por si mesmos como resolver a questão, ela é recomendada para conflitos entre partes que tenham um relacionamento ou vinculo anterior ao problema, como se nota no artigo 165, $\S 3^{\circ}$ do novo Código de Processo Civil (BRASIL, 2015). Diz o referido 
artigo que o mediador atuará preferencialmente nos casos em que houve vínculos anteriores entre as partes, ou seja, que tenha uma relação que se pretenda manter no mínimo civilizatório.

Além disso, no mesmo artigo o Código ainda ajuda a combater uma pequena divergência doutrinaria quanto à finalidade da mediação e da conciliação, ele informa que a mediação tem como finalidade restabelecer a comunicação, enquanto a conciliação é a realização de um acordo.

Vale destacar algumas características da mediação que foram responsáveis por tornála popular no momento de descrédito com o Poder Judiciário. Várias dessas características são princípios e vantagens do método hora estudado, como por exemplo: a celeridade, pois as sessões de mediação têm tempo determinado e acordado previamente entre as partes; a voluntariedade, vez que a sessão e o acordo só podem ocorrer se ambos os participantes quiserem; e o sigilo, pois nada do que ocorreu ou foi dito na sessão pode ser comentado fora dela, nem usado em outros processos, inclusive o mediador não pode ser chamado como testemunha.

Além dos pontos que são princípios e vantagens, outros benefícios que mais se destacam são a satisfação das partes e o cumprimento dos acordos realizados, conforme Morais e Spengler (2008). Ambos são resultantes do fato de que, ao participarem ativamente da tomada da decisão do conflito, as partes sentem que a deliberação é mais justa por elas mesmas estarem construindo-a; dessa forma compreendem que suas limitações serão respeitadas e que suas opiniões para resolver o problema são ouvidas, por isso elas se sentem reconhecidas e valoradas.

É importante ressaltar, nos dizeres de Gomes (2013), que um dos motivos pelos quais as decisões judiciais não conseguem o mesmo êxito que os acordos realizados por meio da mediação é que o meio da jurisdição cria uma visão adversarial dos conflitos, de modo que as partes não se vejam como pessoas capazes de solucionar seus problemas e sim como adversárias.

Explica Gomes (2013) que as partes em oposição, acompanhadas de seus respectivos advogados, desferem ataques uma contra a outra durante todo o processo. O resultado dessa peleja compreende em quem perder o processo ser o errado, ser reconhecido como o sem direito, e quem sair vencedor é reconhecido como o correto. É até interessante notar que a ideia apresentada por Gomes (2013) traz uma lembrança das pelejas que ocorriam na época 
do autotutela, o vencedor da disputa era quem tinha o direito reconhecido, enquanto o perdedor se via sem direito algum.

Em contraposição à ideia de rivalidade durante o processo judicial, e para trazer uma pacificação social, de modo que não apenas se resolva o conflito aparente como no judicial, segundo Gomes (2013), mas que possa restabelecer a convivência civilizada e a conversa entre as partes é que vem a mediação. Tal afirmação comunga com a ideia exposta por Silva (2013, p. 170) que afirma que com a mediação “[...] se adotar, com este método, o caminho dialético, possibilitando a comunicação entre os dissidentes, a transformação da relação conflituosa e a construção de um acordo satisfatório e eficaz.”.

Em outras palavras, entende-se que a mediação, ao trazer o conflito para a análise mais aprofundada, tenta compreendê-lo desde sua causa até o seu ápice, para então buscar uma transformação do conflito em algo positivo para as partes a fim de tentarem se compreender novamente. Algo que não há como ser feito no processo burocrático do método de jurisdição.

De acordo com Silva (2008), a mediação responsabiliza os protagonistas da lide, permitindo que exerçam suas capacidades de elaborar, por eles próprios, uma solução satisfatória e duradoura, informando ainda que o trunfo da mediação é a sensação, ainda que mínima, de responsabilidade, respeito e confiança criada com a restauração do diálogo e da comunicação entre os litigantes.

\footnotetext{
Isso porque o procedimento de mediação, que enfatiza a cooperação ao invés do confronto, é pautado na identificação das reais motivações das partes, de sorte a transparecer os sentimentos de interesse subjacentes ao conflito, possibilitando os dissentes chegarem a um acordo em uma dimensão ampla da problemática, sem palpites de terceiro, através do restabelecimento da comunicação e da transformação do conflito (SILVA, 2013, p. 163)
}

Ademais, para a mediação se apresentar como muito mais vantajosa devem ser analisados os custos, já que é muito menos dispendioso que um processo judicial. Também se vê que na mediação não há a característica da obrigatoriedade para as partes como há nos processos judiciais. E, nela há uma maior flexibilidade, podendo também se flexibilizarem os interesses em jogos (SILVA, 2013).

Vale lembrar que a mediação é utilizada em vários países, inclusive no campo do Direito Internacional, em que a figura do mediador é desempenhada por um representante estatal ou um organismo internacional imparcial e idôneo (SILVA, 2013). 
Na cultura ocidental, a mediação ainda não tem muito uso, mas há algumas regiões que já começam a se destacar nessa área; a União Europeia aparece como uma grande incentivadora de métodos alternativos de conflitos, especialmente a mediação. Na comunidade europeia, aparece em relevo na adoção da mediação a França e Portugal. Já na América Latina a medicação já tem mais força, em razão da tradição indígena e espanhola, destacando-se os países do Equador, Honduras, Colômbia, Paraguai e Argentina, esta merece ser ressaltada, já que utiliza a mediação no direito trabalhista (SILVA, 2013).

Do exposto, fica claro como a mediação é um mecanismo de solução de conflitos de suma importância, que apresenta inúmeras vantagens em relação aos demais mecanismos de conflitos. Inclusive, considerando-se que, atualmente, o Judiciário passa por crise, causada também pelo excesso de demandas judicias, e a mediação surge como um meio de desafogar o sistema, além de que a mediação permite o acesso à Justiça, sem a necessidade de ingressar com um processo burocrático no tribunal, que muitas vezes acaba por se caracterizar em uma verdadeira violação aos direitos humanos e ao princípio da dignidade humana.

Nesse sentido, Vezzulla (2013, p. 68) realiza uma crítica à demasiada dependência dos ocidentais para com o processo judiciário ao dizer que

\footnotetext{
Os tribunais ocidentais, dependentes do Poder Judiciário, normalmente a única via possível para que os cidadãos possam apresentar seus direitos ameaçados ou já desrespeitados por outrem na procura de "justiça", continuam a manter um procedimento que questiona não somente a igualdade frente a lei, mas outros direitos que fazem a dignidade humana.
}

Com tal crítica, compreende-se que o entendimento de Vezzulla é de que o processo judicial, pelo menos na forma que atualmente se apresenta, qual seja moroso, inconstante e adversarial, não pode ser mais considerado o representante da justiça desejada pelos cidadãos, pois quando as demandas adentram em seu recinto acabam sendo resolvidas com métodos ou formas que atentam contra os próprios princípios e ideais de justiça que tais tribunais deveriam trazer.

Por fim, ao observar todas as ponderações sobre a mediação, a jurisdição e a realização da justiça, entende-se que a mediação pode também ser um interessante meio de solução dos conflitos trabalhistas, e, ao mesmo tempo, um meio para aliviar o sistema judiciário trabalhista, mantendo as garantias e direito do trabalhador, portanto os próximos tópicos discorrerão sobre esta possibilidade. 


\subsection{A RELAÇÃO DA MEDIAÇÃO E O DIREITO DO TRABALHO}

Apesar de parecer novidade, a mediação não é um método moderno de resolução de conflito, ela veio de civilizações remotas como a antiga Roma. No Brasil, antes mesmo da Lei $\mathrm{n}^{\circ} 13.140 / 2015$ surgir, a mediação já existia, ainda que não fosse regulamentada, como observado no texto de Amaral (1994). No entanto, é verdade que ela nunca teve um protagonismo forte em comparação com outros métodos alternativos de resolução de conflitos, como a arbitragem, que desde o tempo do Brasil Colônia era forte, no entanto ao longo dos anos foi perdendo sua força para o Judiciário.

Com a informação de que a mediação é mais antiga no ordenamento jurídico pátrio do que se pensa, não é nenhuma surpresa notar que esse método não adversarial de pacificação de lide e o Direito do Trabalho tenham uma vetusta relação, uma vez que, desde o seu surgimento, tanto o Direito quanto a Justiça obreira foram grandes incentivadores das resoluções alternativas de pacificação de lides. Pode-se notar a relação entre a mediação e o direito do trabalho com as palavras de Delgado (2017, p. 1663):

A ordem jurídica trabalhista anterior a 1988 previa a mediação compulsória nos
conflitos laborais coletivos, a ser realizada por autoridades do Ministério do
Trabalho. De fato, a CLT, no campo regulatório da negociação coletiva trabalhista
$\left(\right.$ art. $616, \S \S 1^{\circ}$ e $\left.2^{\circ}\right)$, previa a convocação compulsória para comparecimento perante
os órgãos administrativos especializados do Ministério do Trabalho de sindicatos e
empresas recalcitrantes, visando a dinâmica negocial a ser ali implementada.
Presentes as partes, processava-se a mediação administrativa em direção à
negociação coletiva.

Com o advento da Carta Magna de 1988, a obrigatoriedade de submeter os conflitos laborais coletivos à mediação junto ao Ministério do Trabalho acabou. Porém, como o próprio Delgado (2017) informa, ainda que a constituição tenha acabado com a compulsoriedade da mediação coletiva, não há dúvidas que a possibilidade fático-jurídica da realização de mediação voluntária permanece. Tanto permaneceu quanto houve a ampliação dos agentes que poderiam atuar como mediadores de conflitos trabalhistas coletivos

A Lei 10.192/01 deixa claro que as partes podem, de comum acordo, escolher o mediador ou este será designado pelo Ministério do Trabalho e Emprego.

Dessa forma, não apenas os agentes do Ministério do Trabalho poderiam ser mediadores como quaisquer profissionais civis que fossem especialistas na dinâmica da mediação coletiva poderiam ser escolhidos pelas partes. Por fim, Delgado (2017) ainda 
informa que ao longo dos anos, a lista de possíveis mediadores e órgãos - que seriam capazes de realizar a mediação coletiva - foi aumentando sendo incluído nela o Ministério Público do Trabalho e seus procuradores, os próprios Tribunais Regionais do Trabalho e o Tribunal Superior do Trabalho.

Com o advento da Lei 13.140/15 (BRASIL, 2015), abriu-se a possibilidade de ocorrer mediação em direitos indisponíveis transigíveis, por força do seu artigo $3^{\circ}, \S 2^{\circ}$; a lei ainda estabelecia, em seu artigo 42, parágrafo único que para o caso da mediação trabalhista seria necessária ter uma lei própria para tratar do assunto.

Naturalmente, até antes de a lei de mediação vigorar, o limite usado para quais direitos poderiam ser alvos de uma mediação era o mesmo da arbitragem e da conciliação, por serem formas parecidas de resolução de conflitos, e os direitos que poderiam ser objeto desses meios de resolução eram os direitos patrimoniais disponíveis. Assim, compreendia que a mediação também só poderia tratar sobre tais direitos.

Através da ampliação da Lei 13.140/15, os direitos indisponíveis, que podem ser transigidos, podem ser objeto da mediação, sendo necessária e obrigatória após a realização do acordo a homologação pela Justiça responsável pelo assunto ali tratado.

Na seara do Direito do Trabalho, esse ponto foi muito impactante, pois devido ao princípio da indisponibilidade dos direitos trabalhistas, eles têm esse caráter de serem indisponíveis, no entanto, ao mesmo tempo, há a flexibilização dos direitos trabalhistas, permitindo que os direitos indisponíveis sejam negociados ou flexibilizados, em outras palavras, passiveis de transição.

Com a perspectiva de que os direitos trabalhistas flexibilizados se encaixavam em direitos indisponíveis transigíveis, surgiu o entendimento de que seria possível haver a mediação extrajudicial de direitos trabalhistas individuais.

Para tentar apaziguar novamente o entendimento quanto à questão da mediação trabalhista e para regulamentá-la, enquanto não fosse publicada a lei exigida, o Conselho Superior da Justiça do Trabalho (CSTJ) editou a Resolução ${ }^{\circ}$ 174/2016 que trata justamente da mediação e da conciliação no âmbito da Justiça do Trabalho. Na Resolução n 174/2016 do CSTJ (BRASIL, 2016), há o estabelecimento da mediação judicial trabalhista, que poderá ser realizada tanto para conflitos individuais quanto coletivos, desde que seja realizada no Tribunal Regional do Trabalho e por um mediador que seja servidor público do respectivo TRT supervisionado por um juiz ou que seja o próprio juiz do trabalho. 
Além disso, a resolução proíbe que haja mediação ou conciliação extrajudicial de direitos individuais do trabalho, dizendo ainda que não será homologado nenhum acordo que venha de câmaras privadas de mediação ou conciliação. É o que se compreende com o estabelecido na parte final do $\$ 6^{\circ}$ do artigo $7^{\circ}$ da Resolução $n^{\circ}$ 174/2016 (BRASIL, 2016) “[...] sendo inaplicáveis à Justiça do Trabalho as disposições referentes às Câmaras Privadas de Conciliação, Mediação e Arbitragem, e normas atinentes à conciliação e mediação extrajudicial e pré-processual previstas no NCPC.".

Ressalta-se que o entendimento pacífico que previa que a mediação extrajudicial não poderia ocorrer na Justiça do Trabalho durou pouco, pois já em 2017 a reforma trabalhista trouxe novos elementos que reacenderam a discussão sobre a possibilidade de a mediação extrajudicial trabalhista acontecer. Em face do novo cenário, será discutida, no item seguinte, a possibilidade da mediação extrajudicial no âmbito na Justiça do Trabalho.

\section{A INFLUÊNCIA DA REFORMA TRABALHISTA NA POSSIBILIDADE DA MEDIAÇÃO EXTRAJUDICIAL NO ÂMBITO TRABALHISTA}

Como relatado em tópico anterior, a reforma trabalhista de 2017 trouxe novamente o fôlego para a discussão da possibilidade da mediação extrajudicial nas relações individuais trabalhistas. Ao ler a lei 13.467/17 (BRASIL, 2017), pode-se destacar que as duas principais causas para esse novo ânimo da discussão são a forte flexibilização dos direitos trabalhistas, prevista na citada lei, e a criação do procedimento de homologação da jurisdição voluntária.

A primeira causa elencada como motivo do ressurgimento da discussão sobre a possibilidade da mediação extrajudicial trabalhista foi a flexibilização dos direitos obreiros, que, de acordo com Delgado (2017), seria a possibilidade jurídica estipulada por norma estatal ou por norma coletiva negociada, de atenuação ou diminuição da força imperativa das normas que compõe o Direito do Trabalho, de modo a mitigar a amplitude de seus comandos e/ou os parâmetros próprios para a sua incidência. Em outras palavras, é a minoração da imperatividade das normas trabalhistas ou de seus efeitos.

O princípio da imperatividade informa que as normas trabalhistas são de ordem pública, logo que devem ser compridas e não podem ser afastadas. Desse princípio se desdobra outro brocardo muito importante, o da indisponibilidade do direito do trabalho. Deste modo conclui-se que os Direitos Trabalhistas são indisponíveis. 
Como já foi dito no tópico anterior, a flexibilização dos direitos trabalhistas se encaixa perfeitamente na descrição do que seria um direito indisponível transigível, ou seja, todos aqueles direitos trabalhistas que sejam flexibilizados poderiam ser objetos de mediação, de acordo com a Lei 13.140/15 (BRASIL 2015).

Não obstante, é necessário notar que a simples flexibilização dos direitos obreiros não garante que a mediação extrajudicial possa ser realizada, apenas permite que direitos trabalhistas que estejam flexibilizados por norma estatal ou por coletiva negociada sejam usados na mediação. Nesse caso, a mediação judicial, até então, é a única que, de certa forma, tem uma regulamentação.

Há que se ressaltar também que a flexibilização dos direitos obreiros não é nada vantajosa para os trabalhadores, pois os direitos trabalhistas têm uma natureza própria de proteção ao trabalhador, que é a parte hipossuficiente na relação de trabalho, retirar o seu manto de imperatividade e de indisponibilidade é enfraquecer o próprio direito do trabalho.

É verdade que, de forma limitada, a flexibilização pode ser compatível com as normas de proteção trabalhista, uma vez que, ao permitir que os próprios trabalhadores através de seus sindicatos - possam determinar qual a melhor forma de usufruir de seus direitos ou até mesmo criar novos em suas convenções coletivas e acordos coletivos é sempre saudável. E mesmo que haja a diminuição de determinado direito, desde que haja uma compensação igualitária e válida para os empregados, ainda é uma forma saudável de exercer a liberdade contratual mediante um limite protetivo para os empregados. Todavia o que se vê na reforma de 2017 é uma ampliação da flexibilização dos direitos trabalhistas, sem a necessidade de uma compensação equivalente definida, junto ao enfraquecimento do sindicato, da valorização do negociado sobre o legislado e da possibilidade da negociação individual do patrão com o empregado. Infelizmente, este é um cenário muito propenso para abusos por parte dos empregadores.

Compreende-se que o papel da flexibilização é garantir que os direitos trabalhistas individuais possam entrar na categoria de direitos indisponíveis transigíveis para que sejam alvos da mediação, muito mais que garantir que essa possa ser realizada.

Além disso, é válido notar que é por meio da flexibilização também que se estimula a utilização de medidas extrajudiciais de resolução de conflitos, uma vez que ela permite a negociação e transação dos direitos trabalhistas, de modo que os meios extrajudiciais possam versar sobre eles. 
Acrescente-se o fato de que com a nova regra vista no artigo 611-B, XXI, da Lei 13.467/17 (BRASIL, 2017), há que se levar em consideração a possibilidade de que a negociação coletiva possa estabelecer que os conflitos trabalhistas sejam apreciados por meio de uma forma alternativa de resolução de conflitos desde que cumpra os requisitos do caput do referido artigo e não supra ou reduza os direitos listados em seu rol taxativo.

Tal entendimento não foi questionado pelo presente estudo, porém há que se notar que ele é possível, uma vez que em tese o acréscimo de um meio de tratamento para o conflito não suprime nem reduz o direito à ação trabalhista, ele estaria aumentando as possibilidades de resolução da controvérsia.

Nesse caso, sendo esse o entendimento do juiz, ao analisar o acordo ou convenção coletiva, e entendendo que seria possível utilizar os métodos alternativos de ressignificação de conflito, estes estariam validados por norma coletiva. Por conta da valoração do negociado sobre o legislado, poderia a mediação extrajudicial ser permitida mediante acordo ou convenção coletiva, o que não garante que fosse trazer benefícios aos empregados, haja vista que não há a lei que a regulamente ainda.

A segunda causa que se apresenta como motivo para compreender que a mediação extrajudicial poderia ocorrer na Justiça obreira é a criação da jurisdição voluntária, e sua homologação, que nada mais é que a homologação do acordo extrajudicial pelas varas trabalhista, uma vez que a própria Lei $\mathrm{n}^{\circ}$ 13.140/15 (BRASIL, 2015) estabelece que no caso de mediações que versem sobre direitos indisponíveis e transigíveis, o acordo deve, obrigatoriamente, ser homologado pela Justiça.

O procedimento de homologação de jurisdição voluntária está estabelecido no capítulo III-A da Lei 13.467/17, que é composto pelos artigos 855-B a 855-E, os quais determinam como ocorrerá o procedimento da homologação, desde como deve ser feito o pedido até a possibilidade de o juiz marcar audiência, caso entenda por necessário, porém é o artigo 652, alínea f da Lei 13.467/17 (BRASIL 2017) que estipula que é de competência das varas trabalhistas a decisão quanto à homologação de acordo extrajudicial em matéria competente à Justiça do Trabalho.

Em virtude dos artigos citados, compreendeu-se que a reforma trabalhista estaria de maneira indireta permitindo que a mediação extrajudicial ocorra nas relações trabalhistas individuais, uma vez que as formas alternativas de resolução de conflito que geram acordo são a mediação, a conciliação e a negociação, ou seja, os meios autocompositivos, lembrando que 
a autotutela é proibida no ordenamento jurídico brasileiro, existindo apenas algumas exceções, e que a arbitragem, um procedimento heterocompositivo, gera ao seu final o laudo ou sentença arbitral.

Esse é o motivo mais forte pelo qual este estudo entende que as formas extrajudiciais da mediação e da conciliação sejam possíveis na seara trabalhista, compreendendo que a reforma, ainda que de forma indireta - pois não há expressamente a permissão - teria concedido a utilização desses meios de resolução de conflito; uma vez que não teria porque regulamentar a homologação do acordo extrajudicial se os métodos que geram o acordo extrajudicial não fossem autorizados.

Apesar de ser uma lógica racional e compreensível, deve-se notar que há um grande empecilho que a reforma trabalhista não conseguiu cumprir para que fosse legalmente permitida a mediação extrajudicial trabalhista. A lei de mediação (BRASIL 2015) estabelece claramente no parágrafo único do artigo 42 que a “[...] mediação nas relações do trabalho será regulada por lei própria.". Lei própria é aquela que trata especialmente sobre uma determinada matéria, ou seja, é uma lei específica sobre o assunto. Primeiro, nota-se que essa é uma norma de eficácia contida, ou seja, que para a sua eficácia seja efetivamente válida ela deve cumprir uma condição, nesse caso a de existir uma lei regulamentadora para a mediação nos direitos trabalhistas.

A reforma trabalhista de 2017 não é uma lei de matéria específica, ela trata sobre diversos direitos obreiros, além de que ela não faz nenhuma menção expressa sobre a mediação, nem como ela ocorrerá nas relações trabalhistas e nem autorizando sua utilização, o que é necessária numa lei própria. Em outras palavras, a reforma não cumpriu o papel necessário que a Lei $\mathrm{n}^{\circ}$ 13.140/15 exige, dessa forma não pode ser considerada uma lei própria, pois não houve sequer a menção à mediação em seus artigos.

Por conta disso, ainda que possa se considerar que a reforma trabalhista de forma indireta pretende permitir a utilização de meios extrajudiciais de resolução de conflitos, como a mediação e a conciliação, ela não as permitiu expressamente, o que para a utilização da mediação seria o necessário por ser uma norma de eficácia contida.

No entanto, a reforma teve um grande papel, de fato, para a mediação trabalhista ao enquadrar mais direitos obreiros na categoria de direitos indisponíveis transigíveis e no óbvio incentivo à utilização dos meios extrajudiciais de ressignificação de conflitos ao criar o procedimento de homologação da jurisdição voluntária para cumprir os requisitos estabelecidos na Lei $\mathrm{n}^{\circ} 13.140 / 15$. 


\section{CONCLUSÃO}

Após compreender o que é mediação e a sua relação com a Justiça obreira, bem como analisar o impacto da reforma trabalhista e da lei de mediação na relação entre as partes e Direito do Trabalho pode-se notar que não há incompatibilidades entre a mediação, extra ou judicial, e a Justiça do Trabalho.

A Justiça do Trabalho, dentre as demais, sempre foi a que mais incentivou a autocomoposição desde sua criação à utilização de outros métodos de resolução de conflitos além da jurisdição, fossem judiciais ou não. Por tal motivo é lógico dizer que a mediação é completamente compatível com os direitos trabalhistas, ainda que até 2015 ela só pudesse ser usada no âmbito dos direitos coletivos dessa seara do direito.

Com o advento da Lei $\mathrm{n}^{\circ} 13.140 / 15$, houve uma ampliação no rol dos direitos que poderiam ser objetos da mediação, trazendo com tal mudança a possibilidade da mediação não apenas para o direito coletivo trabalhista, como também para o individual. No entanto, essa mesma lei criou uma condição que permanece sem ser atendida, uma vez que ela determina a regulamentação da mediação trabalhista por uma lei própria, a qual não existe. Deixando claro que até que essa lei seja publicada, não há como haver a mediação extrajudicial trabalhista sobre direitos individuais.

Por fim, ressalta-se que ainda que não tenha cumprido o requisito de ser uma lei própria que regulamente a mediação nas relações trabalhistas, a reforma trabalhista de 2017 foi de grande influência para o debate sobre a utilização ou não da mediação no direito individual do trabalho, uma vez que ela visivelmente estimula o uso de meios alternativos à justiça.

Pode-se notar a intenção de garantir que haja como ocorrer a mediação extrajudicial nas relações trabalhistas, uma vez que a criação da homologação de acordos extrajudiciais veio para atender regras estabelecidas pela Lei $\mathrm{n}^{\circ} 13.140 / 15$ da obrigatoriedade da homologação judicial em casos de direitos indisponíveis transigíveis e a própria flexibilização para garantir que os direitos trabalhistas que têm status de indisponíveis possam ser negociados.

Conclui-se com tal estudo que há a possibilidade da utilização da mediação extrajudicial nas relações individuais trabalhistas e que a reforma obreira de 2017 tem a clara intenção de estimular e garantir que a mediação obreira tenha como ocorrer. Contudo, ainda 
não se pode concordar plenamente com a sua utilização, visto que a condição que a lei de mediação estabeleceu para que pudesse haver a mediação trabalhista ainda não foi realizada.

\section{REFERÊNCIAS BIBLIOGRÁFICAS}

AMARAL, Lídia Miranda de Lima. Mediação e arbitragem: uma solução para os conflitos trabalhistas no Brasil. São Paulo: LTr, 1994.

AZEVEDO, André Gomma. Novos desafios de acesso à justiça. In: SILVA, Luciana Aboim Machado Gonçalves da (Org). Mediação de conflitos. São Paulo: Ed. Atlas, 2013. p. 3-22.

BRASIL. Lei N. 13.140, de 26 de junho de 2015. Dispõe sobre a Mediação entre particulares como meio de solução de controvérsias e sobre a autocomposiçao de conflitos no âmbito da administração pública. Diário Oficial [da] União - Seção 1 - 29/6/2015, Página 4. Brasília, DF, 2015.

Lei N. 13.467, de 13 de julho de 2017. Altera a Consolidação das Leis do Trabalho (CLT), aprovada pelo Decreto-Lei $\mathrm{n}^{\circ} 5.452$, de $1^{\circ}$ de maio de 1943, e as Leis $\mathrm{n}^{\circ} \mathrm{s} 6.019$, de 3 de janeiro de 1974, 8.036, de 11 de maio de 1990, e 8.212, de 24 de julho de 1991, a fim de adequar a legislação às novas relações de trabalho. Diário Oficial [da] União - Seção 1 14/7/2017, Página 1 Brasília, DF, 2017.

Conselho Superior da Justiça do Trabalho. Resolução CSJT n. ${ }^{\circ}$ 174, de 30 de setembro de 2016. Dispõe sobre a política judiciária nacional de tratamento adequado das disputas de interesses no âmbito do Poder Judiciário Trabalhista e dá outras providências. Diário Eletrônico [da] Justiça [do] Trabalho, n. 2079, 5 out. 2016. Caderno Administrativo [do] Conselho Superior da Justiça do Trabalho, p. 1-6. Brasília, DF, 2016.

CAPPELlETTI, Mauro; GARTH, Bryant. El Acesso a la justicia. La tendencia en el movimiento mundial para hacer efectivos los derechos. México: Fondo Economico, 1996.

DELGADO, Maurício Godinho. Curso do direito do trabalho. 16.ed. rev. e ampl. São Paulo: LTr, 2017.

GOMES, Ana Carolina N. G. F. A mediação de conflitos e a atuação da defensoria pública. In: ANDRADE, Mariana Dionísio de; QUARANTA, Roberta Madeira (orgs). Acesso à justiça: textos em homenagem à Maria Tereza Sadek. 2.ed. Florianópolis: Conceito Editorial, 2013.

FLORES, Joaquín Herrera. La complejidad de los derechos humanos. Bases teóricas para una redefinición contextualizada. En: REID Revista Internacional de Direito e Cidadania $\mathrm{N}^{\circ} 1$, Vol. 1. Junho 2008. Instituto Estudos Direito e Cidadania. Sao Paulo, 2008. (pp. 103-135).

MORAIS, José Luis Bolzan de; SPENGLER, Fabiana Marion. Mediação e arbitragem: alternativa à jurisdição. 2.ed. rev. e ampl. Porto Alegre: Livraria do Advogado Editora, 2008. 
SILVA, Antônio Hélio. Arbitragem, mediação e conciliação. In: LEITE, Eduardo de Oliveira (coord). Grandes temas da atualidade: mediação, arbitragem e conciliação. 1.ed. Rio de Janeiro: Forense, 2008.

SILVA, Luciana Aboim Machaçado da. Mediação interdisciplinar: um caminho viável à autocomposição dos conflitos familiares. Diké: Revista do Mestrado em Direito da Universidade Federal de Sergipe. 1 ed. v. 1. no 1 . São Cristóvão: Editora UFS, jul./ dez. 2011.

SILVA, Luciana Aboim Machado Gonçalves da. Mediação interdisciplinar de conflitos: mecanismos apropriado para resolução de conflitos familiares. In (Org). Mediação de Conflitos. São Paulo: Ed. Atlas, 2013. p. 160-180.

VEZULLA, Juan Carlos. A mediação para uma análise da abordagem dos conflitos à luz dos direitos humanos, o acesso à justiça e o respeito à dignidade humana. In: SILVA, Luciana Aboim Machado Gonçalves da (Org). Mediação de Conflitos. São Paulo: Ed. Atlas, 2013. p. 63-93.

VEZZULlA, Juan Carlos. Adolescente, família, escola e lei. A mediação dos conflitos. Lisboa: Agora comunicação, 2006.

TARTUCE, Fernanda. Mediação nos conflitos civis. 3.ed. Rev., Atual., Ampl. Rio de Janeiro: Forense; São Paulo: Método, 2016. 